\title{
The Giant Tortoises of the Galapagos Islands
}

\section{Their Present Status and Future Chances}

$$
\text { By D. W. Snow }
$$

THE Charles Darwin Research Station in the Galapagos has as its most urgent duty the protection of the remaining giant tortoises, which, besides being one of the most interesting and spectacular elements in the unique fauna, and giving the islands their name, are at present in greater danger of extinction than any other native animals. Accurate knowledge of their present status is a prerequisite of conservation, and this is not easy to obtain in the extremely difficult terrain where most of the surviving tortoises live. This paper summarises very briefly the previously available information: its main purpose is to present the new information which has been obtained in the last year and a half (time of writing, August, 1964), to discuss the factors threatening their continued existence, and to outline the conservation measures which have already been taken and those that are planned for the future.

It may be recalled that originally tortoises occurred on nearly all the main islands of the Galapagos, often in great numbers (Fig. 1). Then

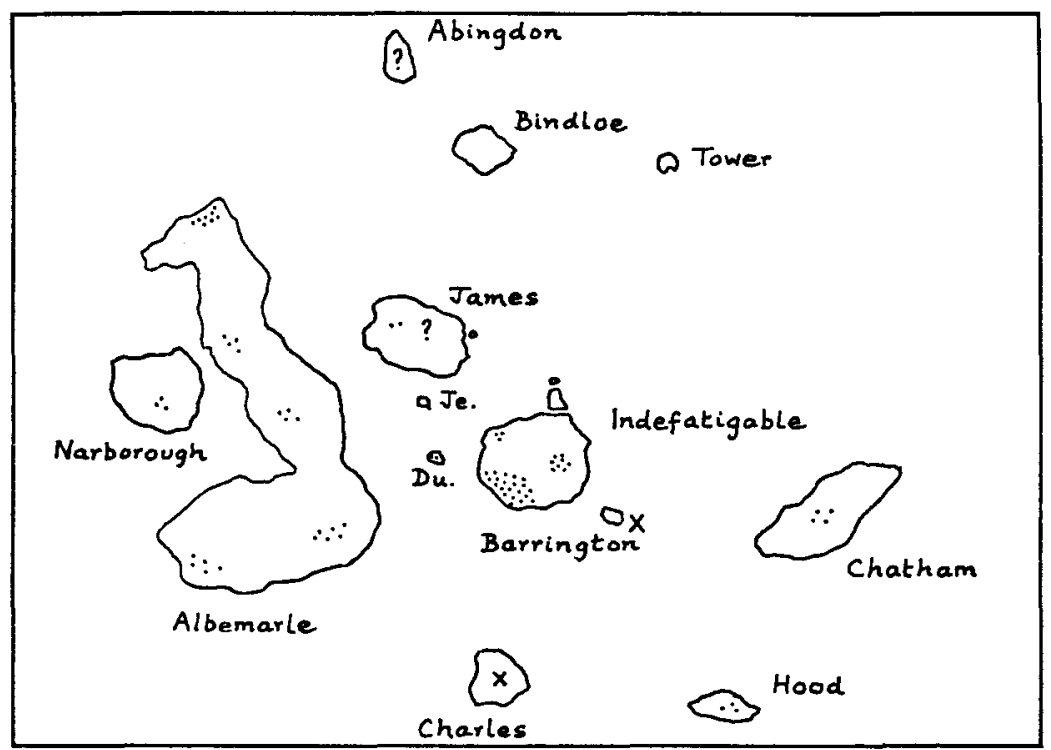

Fig. I : The main islands of the Galapagos. All those shown except Bindloe, Tower and probably Jervis have, or had, native tortoise populations. Dots indicate areas where tortoises still occur. A cross indicates that the native tortoise is definitely extinct. Du. : Duncan. Je. : Jervis. 
in the eighteenth and nineteenth centuries they were removed in huge numbers for their meat and oil, first by the buccaneers and other seamen, and then more systematically by the whalers. The geologist $\mathrm{G}$. Baur, who visited the islands in 1891, thought that about ten million tortoises had been removed up to that time. Townsend (1925) considered this figure too high, but even so his finding that 13,000 were taken by a small fraction of the American whaling fleet between 1831 and 1867 shows that altogether, during two centuries of exploitation, the number taken must have been in the hundreds of thousands. Furthermore, the sailors took the largest individuals which it was convenient to carry, and these were usually adult females. Captain Porter, of the U.S. Frigate Essex, wrote that of 14 tons of tortoises taken aboard in 1812, only three were males. Not surprisingly, males have predominated in the collections made in the twentieth century. Nor is it surprising that Townsend and others, considering this tremendous toll and the simultaneous introduction of domestic animals, have concluded that the Galapagos tortoises are doomed in their native habitat.

\section{A Series of Dry "Wet " Seasons}

An adverse factor in the more recent history of the Galapagos tortoises has been the very severe drought to which the archipelago has been subjected in the last twenty years. Exact statistics are lacking, but according to the most reliable of the settlers, who have been in the islands for the last twenty-five years or more, the "wet" seasons (normally JanuaryApril) have been extremely dry since about 1942, with the exception of one very wet year, 1953. It is now difficult to imagine, for example, waterfalls on Barrington (Santa $\mathrm{Fe}$ ) ${ }^{\star}$ being visible from Academy Bay 15 miles away, or extensive ponds with lush vegetation and ducks a few hundred yards inland from where the Charles Darwin Research Station now stands; but these were seen by the settlers in the 1920s and 1930s. On the other hand, some of the earlier accounts have stressed the awful barrenness and aridity of the Galapagos. A long series of statistics would probably show that the archipelago is subject to wide climatic fluctuations, especially in rainfall, and in the past history of the islands correspondingly great fluctuations in the populations of the native animals have probably been the rule rather than the exception. What must have been so disastrous for the tortoises, and no doubt for other native animals, is the fact that a markedly dry period has followed closely after the introduction of goats and other domestic animals, resulting in degradation of the vegetation to a degree hitherto probably unknown. The effect has been especially serious on the more arid such as Hood (Española) and Barrington.

It is not the purpose of this paper to deal with the systematics of the Galapagos tortoises, except to note that each island has, or had, its own race of tortoise, while Albemarle (Isabela), the largest island, has five races isolated from one another on its five great volcanoes. Thus the extinction of any one of the island populations involves an irreparable loss of a unique form of life.

* Since the English names of the different islands have been generally used in the biological literature, they are retained here. The Spanish name is given in parentheses when each island is mentioned for the first time. 


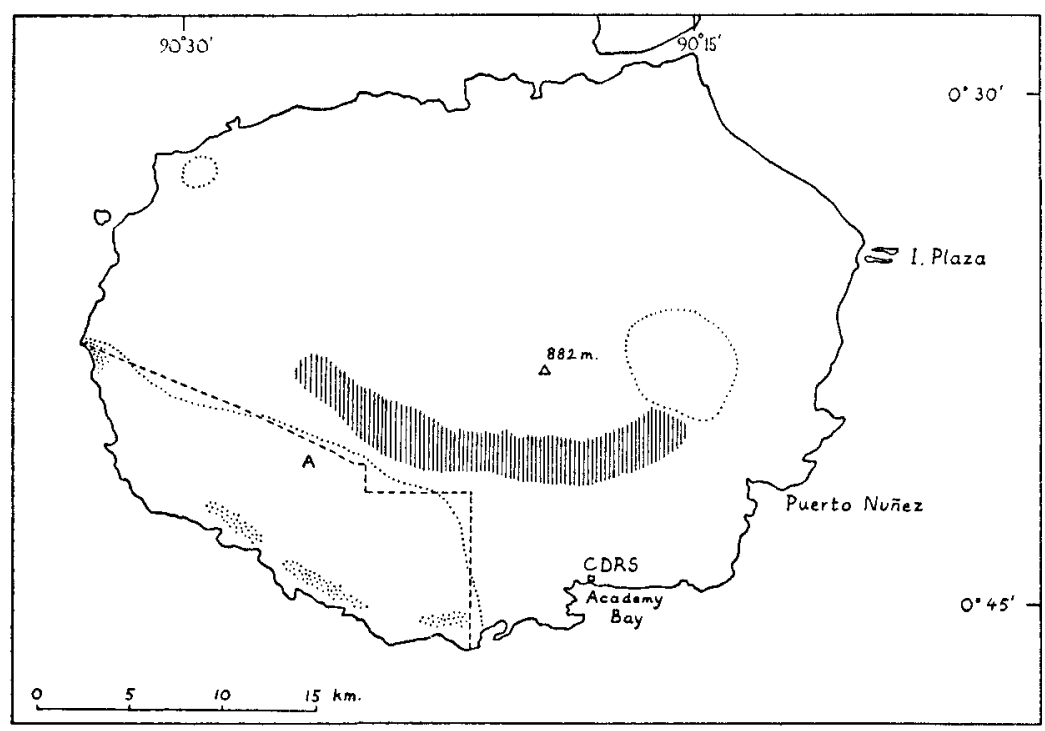

Fig. 2 : Indefatigable Island (Santa Cruz), showing approximate limits of the present tortoise populations (dotted lines), the boundary of the tortoise reserve (broken line), known tortoise nesting areas (dotted patches), and approximate area of farmland (vertical shading). CDRS : site of the Charles Darwin Research Station.

Indefatigable. - The largest surviving tortoise populations are on Indefatigable (Santa Cruz) and Albemarle. Since the Research Station is on the former, within a few miles of the edge of the tortoise country, this population is now relatively well known. Apart from a small and atypical group in the north-west of the island (to be discussed later), the Indefatigable tortoises are to be found in two areas, in the south-west and eastcentral parts of the island (Fig. 2). Undoubtedly these two populations were continuous not many years ago, as is attested by the remains of dead tortoises found in the intervening area (e.g. Bowman, 1960); but it is probable that this intervening zone, to the north of Academy Bay, was always less favoured, since the tortoises descend to the low-lying parts near the coast to lay their eggs, and a series of almost sheer inland cliffs or " barrancos" makes the coast in the neighbourhood of Academy Bay virtually inaccessible to tortoises coming from inland.

In July, 1960, a local worker under the direction of $\mathrm{R}$. Lévêque, then Director of the Research Station, began to mark the tortoises by painting numbers on the carapace, and by the end of 1961 about 1,000 had been marked in this way. However, paint was clearly unsatisfactory as a permanent method of marking such long-lived animals, and in April, 1962, Lévêque's successor, A. Brosset, with advice from Dr. C. C. Carpenter of the University of Oklahoma, began a system of marking by cutting small notches in the marginal plates according to a code which allows for 
the marking of 10,000 different individuals. (Tortoises less than about $37 \mathrm{~cm}$. long cannot be marked in this way as their shells are too thin.) Marking by this method has continued regularly ever since, and by the end of June, 1964, over 700 individuals had been marked.

In three inland areas in the south-west of the island where there are semi-permanent ponds and good pastures, the majority of the tortoises are now marked. These areas almost certainly contain the greatest concentrations of adult tortoises to be found in the island; but there are rather large areas further west which are not yet thoroughly explored, and the northern and eastern limits of the east-central populations are not well known. Hence any estimate of the total number of tortoises of a size large enough to be marked must depend to a large extent on guesswork. Tentatively, 1,500-2,000 would appear a reasonable figure.

The females of the south-west group lay their eggs near the coast, in the areas indicated in Fig. 1 and probably elsewhere. The nesting areas of the eastern group have yet to be found : probably they lie near the coast, between the Islas Plaza and Puerto Nuñez, where D. Cavagnaro found open areas with patches of deep soil suitable for nesting tortoises about two miles in from the coast. It is generally assumed by the local people, probably correctly, that the eggs are laid near the coast because the weather in the hills is too cold and wet. Marking has shown that males as well as females migrate down to the coast. For example, one large male was marked on August 22nd, 1962, at the place locally known as El Chato ( $A$ in Fig. 2), an area of ponds and pastures near the upper limit of the tortoises' range ; it was then found on March 20th, 1963, by the coast $6 \mathrm{~km}$. to the south-west; and then on May 7th was found back again at El Chato, where it was checked again on April 13th, 1964. However, other males appear very sedentary, having been found so often within the same small area over a period of a year or more that it seems unlikely that they can have visited the coast in that period.

Further marking and re-checking of marked individuals may be expected to throw more light on the movements of marked individuals, as well as growth and survival rates and other aspects of tortoise biology, which it is not the purpose of the present paper to pursue any further.

It is impossible even to guess the number of small tortoises in the population. They are of course much harder to find than the large ones, and occur mainly in the coastal areas which have been less thoroughly worked than the inland feeding areas. Of nearly 300 tortoises marked in the three main areas of concentration inland in the south-western sector, only two had a curved length (as defined by Van Denburgh 1914) of less than $50 \mathrm{~cm}$., and most were much larger than this. By contrast, 46 out of 172 marked at the nesting areas near the coast were less than $50 \mathrm{~cm}$. What is certain is that under present conditions only a small fraction of those that hatch reach maturity.

The survival of this relatively flourishing population is threatened in five ways. (1) Human settlers have already taken over a large part of the former tortoise country and converted it into farmland, and they may occupy more in the future. (2) Farmers from the hills still enter the tortoise country and kill the adults for meat and oil. (3) Fishermen still 


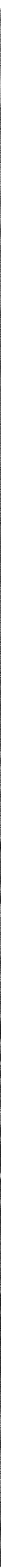

\section{GALAPAGOS TORTOISE}

D. W. Snow

Plate 1: The old male saddle-backed tortoise on Indefatigable feeding on a cactus pad from the opuntia tree close behind him. The devastation of the undergrowth is mainly https://doi.org/10.1017/50030605300003458 Pulthinearke of graattsige University Press 


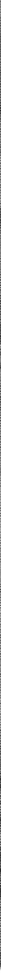

Plate 5 : Measuring a typical dome-shaped tortoise on Indefatigable.

D. W. Snow

Plate 6 : Devastated vegetation on Indefatigable, and the culprits.

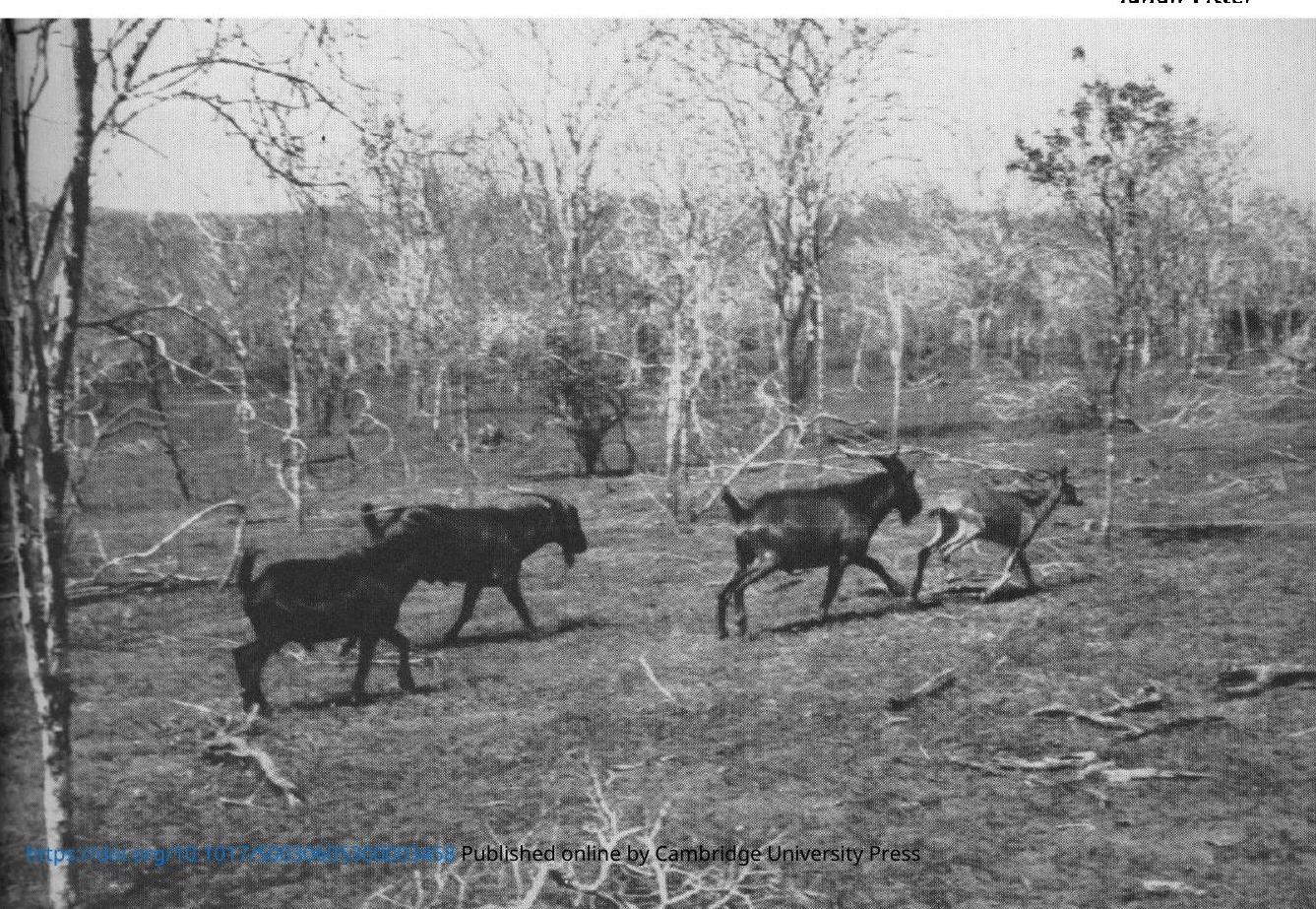



collect young tortoises from the coast for sale or export to the continent, and kill the nesting females for meat and oil. (4) Feral pigs kill the young tortoises, and at least some individual pigs can tackle quite well-grown tortoises, overturning them and attacking the soft parts round the base of the limbs. (5) Goats, cattle and donkeys compete with the tortoises for their food.

(1) The Charles Darwin Research Station has recently been empowered by the Government of Ecuador to take almost any measures it deems necessary for the safeguarding of the native fauna and flora. One of the first measures has been to demarcate a reserve for the Indefatigable tortoises, embracing the greater part of the tortoise country in the southwest of the island (Fig. 2). The administration of this reserve is in the hands of the Station, with the collaboration of the local authorities. Further human exploitation of this area is now forbidden, and entry is limited to permit-holders. Thus there is every hope that the tortoises will never be deprived of the most important part of their remaining territory, though further human encroachment may well jeopardise the east-central population.

(2) and (3). The creating of the tortoise reserve should also check the further depredations of farmers and fishermen, though control will probably not be completely effective for some time. The problem is basically financial, since control depends on the employment of an adequate number of guards. At present a conservation officer and one warden are employed, but later, especially at the nesting season, additional wardens will be required. It should also be added that a more enlightened opinion is slowly gaining ground among the settlers: there is now at least the beginning of a feeling of pride in and respect for their native animals.

(4) Systematic shooting seems the only way to deal with the pigs, and this has been carried out, on a small scale, for the last three years. Total extermination by shooting is hardly possible, but it may be hoped that the pig population can be kept low enough to allow the survival of a fraction of the young tortoises. Perhaps as a result of the prolonged drought, the pigs themselves in recent years appear to have been suffering from food shortage. They are now often emaciated and yield almost no fat, whereas formerly an average pig would yield about 5 gallons. This may well have resulted in their turning more and more to tortoises as a source of food.

(5) It is not easy to assess the effects of the feral cattle, donkeys and goats on the tortoise population. It must be stressed that they are all comparatively recent introductions on Indefatigable and have not yet reached a balance with the environment, if indeed any balance is possible (goats were introduced about 1925, cattle about 1923, donkeys probably about the same time). In the upper and more humid areas the situation is perhaps not immediately serious, as large numbers of full-grown tortoises can and do co-exist with the introduced animals, evidently finding enough food to be able to lead a very sedentary life. However, the long-term effects may well be serious, as browsing by the introduced animals has almost completely stopped regeneration of some of the most important trees. In the dry coastal zone the situation is worse. The 
vegetation is being devastated by goats, and the young tortoises must suffer from the reduction of their food supply and probably also from the destruction of the cover, which may expose them to predation by pigs.

\section{The Saddle-backed Tortoises}

Separated by about $10 \mathrm{~km}$. from the known limits of the main tortoise population in the south-west, a small population of very distinct tortoises occurs in the north-west of the island. It was discovered by the Angermeyer brothers, residents of Academy Bay, in 1962. So far, in spite of intensive searching, only seven individuals have been found, including one old male (Plate 1) and six smaller ones probably all less than 5 years old. One very young tortoise was also found dead. The male is of an extreme saddle-backed type, resembling the tortoises of Abingdon (Pinta), and very different from the typical dome-shaped tortoises of Indefatigable (Plate 5). The largest of the six smaller individuals (curved length $46 \mathrm{~cm}$.) is also beginning to develop the saddle-backed shape.

This saddle-backed population poses a problem, which unfortunately may not be soluble. The old male very closely resembles the Abingdon tortoise or the tortoise of the northern volcano of Albemarle. It is not unlike the Duncan tortoise, but is larger than any of the twenty-five males collected from Duncan by the Academy Expedition of 1905-6. It could certainly not be referred to any other known race. Tortoises have at times been transported from one island to another, so these may be the descendants of a few tortoises introduced from Abingdon or northern Albemarle. Perhaps the old male himself was introduced; but if so, it is of interest that he is breeding and producing offspring also of the saddle-backed type. No adult female has yet been found in the area.

On the other hand, it is conceivable but unlikely that there are in fact two native forms of tortoise in the island. The area in the north-west is to some extent isolated from the rest of the island by rough and fissured lava, and if the degree of isolation has been sufficient a distinct race might have evolved. Since the area is dry, it would then not be surprising if a saddlebacked form had evolved, since there is a correlation between the carapace of Galapagos tortoises and their environment, the dome shape being characteristic of the more humid and the saddle-backed shape of the more arid environments. Further investigation of this population is urgent.

Whatever its origin, this group must be in danger of extinction. The area is dry and supports a very scanty herbaceous vegetation, and goats are abundant. The tortoises at present appear to be subsisting entirely on the pads of Opuntia, leaves of Castela galapageia, a common shrub, and grass when it is available. Fortunately goats avoid Castela, but Opuntia and grass are important items in their diet.

Albemarle.-The extremely inhospitable terrain of Albemarle and its great size have so far prevented thorough exploration. It is well known since the work of the Academy Expedition that five different races of tortoises lived on the slopes of the five great volcanoes which together form the island. The Research Station has so far made only preliminary attempts to investigate their present status. 
Volcan Wolf. * Tortoises are known to be still quite abundant on the north slope of this great volcano. It is one of the chief areas from which fishermen still collect young ones for export to the continent. Dowling (1962) found several young individuals at about 800 feet. On May 19th, 1964 , a day's search by the author, $M$. Castro and D. Cavagnaro resulted in the finding of twelve tortoises, at various heights between 230 and 600 feet. Considering the great extent of the northern slopes of this volcano, and the small area thoroughly searched (perhaps $1 \mathrm{sq} . \mathrm{km}$.), it seems certain that there is a total population of many hundreds of individuals. Tortoise tracks are numerous, leading up and down the rough gullies which score the mountain side. Ten of the tortoises found were of medium size (curved lengths $54-70.5 \mathrm{~cm}$.). One was much smaller $(22.5 \mathrm{~cm}$.), and one, an old male, was considerably larger $(83 \mathrm{~cm}$.). This last when found was actively proceeding inland, climbing a very steep slope up a narrow broken gully. It was still only 230 feet above sea level and had just left a much broken area of tumbled lava. Indeed the whole of this country seems almost as inhospitable for tortoises as it is for human beings, and it is this that has ensured their survival in good numbers. Furthermore, there are no goats, cats being the only feral animals to have reached the northern end of Albemarle so far. The many tortoise droppings examined contained only the remains of Opuntia pads, Castela leaves, and grass.

Conservation of this most important population, which must rank with the Indefatigable population in size, may be promoted by posting guards to patrol the landing places during the fishing season, and it is hoped to do this in the coming years.

Volcan Darwin. Hardly anything is known of the recent status of this population. Since members of the Academy Expedition found them to be not uncommon in 1905, the only available information is that remains of dead young tortoises were found in 1953 and 1957 near Tagus Cove (Eibl-Eibesfeldt, 1959, Bowman, 1960). On October 1st, 1963, the author climbed to $3,000 \mathrm{ft}$. on the west slope of the volcano, starting from Tagus Cove. At an altitude of about 2,000 ft., the fresh droppings of a large tortoise were found, still moist, as well as some tortoise trails, but no tortoises were seen. On present evidence it can be concluded that the tortoise population still survives, but that it has declined since 1905. There are as yet no goats on this mountain.

Volcan Alcedo. The Academy Expedition found only a single tortoise on this mountain, and reported that the population had been very thoroughly exploited by the natives. Since then, there have apparently been no further reports.

From August 16th to 19 th, 1963, M. Castro carried out a reconnaissance of the north-east side of the volcano, ascending to the rim of the crater and spending two nights high up on the mountain. He saw no tortoises, but about $5 \mathrm{~km}$. north of the rim of the crater he found an area where

* The modern names of the five volcanoes, from north to south, and the names applied by Van Denburgh (1914) to the race of tortoise inhabiting each, are as follows: Volcan Wolf (North Albemarle Island Tortoise); Volcan Darwin (Tagus Cove Tortoise); Volcan Alcedo (Cowley Mountain Tortoise); Sierra Negra (Villamil Mountain Tortoise); Cerro Azul (Iguana Cove Tortoise). 
tortoises apparently nest, as well as many old droppings, the most recent appearing about two months old. It seemed that the tortoises had moved to another part of the mountain a short time before. Later, in February, 1964, members of the Galapagos International Scientific Project, flying by helicopter over the volcano, saw tortoises feeding on the grassy floor of the crater. In addition to the surviving tortoises, feral dogs, cattle and possibly goats now occur on this mountain.

Sierra Negra and Cerro Azul. No recent investigation has been made of the tortoise populations of the two southern volcanoes of Albemarle. According to local information they still survive, and those on Sierra Negra, above the settlement of Villamil, are still exploited by the settlers. In addition, cattle, pigs, goats and dogs have run wild on this part of the island, so that it may be presumed that the tortoise populations are in serious danger.

Narborough. - The Narborough (Fernandina) tortoise remains a mystery. Rollo Beck collected the only known specimen in 1906 not far below the rim of the crater on the south-east side. In February, 1964, Dr. J. Hendrickson and other members of the Scientific Project camped for a week on one of the " spokes " of vegetation on the south side of the mountain (thin strips of vegetation that have been left between recent lava flows running down either side). An intensive search was made and fresh droppings were found, but no tortoise.

One can only repeat the suggestion originally made by Townsend (1925), that from time to time the Narborough tortoises have been largely killed off by the intense volcanic activity to which this island has been subjected, and that now only a remnant remains which are perhaps on their way to extinction. Whatever the case may be, man has had no hand in it, since Narborough is free from introduced animals and the lava slopes are so forbidding that only a handful of people have ever climbed to the areas where tortoises might live.

Duncan.-The Academy Expedition collected eighty-six tortoises, including sixty-one females, from the small island of Duncan (Pinzon). In spite of this the Duncan population has survived, though it is now much reduced. It is now in great danger from the introduced rats, which eat the tortoises' eggs. Apparently none but adult tortoises have been recorded from Duncan in the present century (Dowling, 1962). Dowling himself found one old tortoise, which was taken for the New York Zoo, and guessed that the population is less than fifty individuals and perhaps less than twenty-five.

Personnel of the Research Station made three visits to Duncan in 1963. On March 27th, the author and $M$. Castro investigated the main crater and the area immediately around it, and found only some recent droppings and signs of old nests but saw no tortoises. On April 29th, Sr. Castro returned with two assistants and spent three days investigating the highest parts of the island. Five tortoises were found and marked. On December 6th he returned again for three days and worked more thoroughly in the same area, finding eighteen new tortoises and only one of those previously marked. So far this year he has paid one more visit, from July 30th to August 4th, finding twenty-three new tortoises and five of those previously 
marked. All those found have been adults. From the proportion of marked to unmarked tortoises found on this last visit it would appear that the population of the area most thoroughly searched is about 140 individuals. This figure may tentatively be taken as the population of the whole island, since the nature of the terrain and vegetation, and absence of droppings, suggested that there can have been few tortoises outside the area, lying to the south of the main peak, where they were actually found.

Food appeared plentiful. The tortoises were recorded feeding on Prosopis, Croton, Tillandsia and Portulaca lutea. It was noted that one feeding on Tillandsia (an epiphyte which here grows on the ground) was always trying to reach the highest leaves, behaviour which has also been noted in the saddle-backed tortoises feeding on Opuntia in north-west Indefatigable and northern Albemarle and which is in contrast to the grazing habits of the dome-shaped tortoises of Indefatigable. The one nest found had been excavated by rats.

In spite of an adequate adult population, the Duncan tortoises are probably doomed unless the rats can be controlled, as it seems clear that the population is no longer reproducing successfully. The only hope is to mount an intensive campaign against the rats, and possible methods are at present under consideration.

James.-Eibl-Eibesfeldt (1959) wrote that the James (Santiago) tortoise " has survived in fairly good numbers on the south-eastern, eastern and north-eastern slopes of the island ". However, this statement appears to be based only on the fact that members of the Academy Expedition, going inland from the east coast in 1906, collected five with great difficulty. Van Denburgh, reporting on the expedition, concluded from this that they seemed to be very near extinction, as did Bowman (1960.) In fact, nothing more was positively known.

Following reports that two tortoises bad been seen inland from the James Bay area on the west side of the island about two years before (reported also by Lévêque, 1963), the Research Station sent a small party to look for them in April 1963. Taking as a guide the caretaker of the salt mine near James Bay, who reported having seen the tortoises, they went inland and on a grassy expanse with manchineel trees (Hippomane) about $4 \mathrm{~km}$. inland and $500 \mathrm{ft}$. above sea level, near the southern edge of the recent lava flow which debouches into James Bay, they found two large tortoises, both probably males (curved lengths 95 and $97.5 \mathrm{~cm}$.). A thorough search revealed no more in the immediate neighbourhood, and no others were found subsequently. Almost certainly they were the two that the guide had seen previously. Later, a number of explorations were made of the main mountain area in the north of the island, from sea level to the highest peaks, and no sign of tortoises was found, although most of this country appears very suitable. But the hardest part of the island to work, the east-central part, where the Academy Expedition found their tortoises, has not been touched, and it is here that future expeditions should now concentrate their efforts.

Jervis.-A thorough search of almost the whole island on May 21, 1963, revealed no sign of tortoises, dead or alive. Since none has been found since the single one taken by the Academy Expedition in 1905, and the 
island is small and comparatively easy to traverse and quite often visited, it must be concluded that no tortoise now exists on Jervis (Rábida). Indeed it may be seriously doubted whether there ever was a native tortoise population on Jervis. Townsend (1925) found that there was only a single reference to Jervis in the logbooks of the whalers which he examined. The ship Zenas Coffin in 1850 " sent in two boats to find terrapins but did not see any". At a time when numerous whaling ships were visiting the Galapagos and taking tortoises from all the other islands, it is strange that Jervis, small and with a good anchorage, should have been neglected if it contained tortoises.

Only two specimens are known of Testudo wallacei, the supposed Jervis tortoise. The first, the type, was of unknown origin : in fact there was no reason at all to suppose that it came from Jervis. Van Denburgh (1914) discussed the question fully and gave reasons, based on minor characters of carapace shape, for referring the single specimen collected by the Academy Expedition to $T$. wallacei, but admitted that there was much doubt in the matter, since it was also much like the tortoises from the south of Albemarle.

Van Denburgh also referred to a rumour that Dr. G. Baur, who was in the Galapagos late in the nineteenth century, had introduced tortoises into Jervis. Furthermore, near the anchorage there still exist the remains of an enclosure made of lava blocks, for which it is hard to suggest any purpose except that it was built to keep tortoises in temporary captivity, perhaps by the crew of a whaling ship which had stocked up with tortoises from elsewhere and were using the safe anchorage of Jervis as their base. One or two of these may well have escaped. All in all, the evidence for the existence of a native tortoise population on Jervis is very unsatisfactory.

Abingdon.- Nothing has been known of the status of the Abingdon tortoise since 1906, when the Academy Expedition found it rare and were able to collect only three specimens. Bowman and Eibl-Eibesfeldt climbed part of the way up the island in 1957 and found none, and in $1963 \mathrm{Dr}$. E. Curio and P. Kramer camped for three weeks on the island, spending most of their time in the lower zones, and also saw none. However, in the very difficult terrain characteristic of the Galapagos Islands, negative evidence of this kind must be treated cautiously. Thus five members of the Scientific Project spent two days camped high on Duncan and saw none, though there is a considerable population near where they camped and the island is not large.

In May, 1964, in an attempt to obtain positive information on the Abingdon tortoises, $M$. Castro and $D$. Cavagnaro camped for nine days on the island and explored all the vegetated parts as thoroughly as possible, from sea level to the highest peak. No sign was found of living tortoises. Towards the end of their stay, happening to look down into a deep fissure, Castro saw the remains of a dead tortoise. Subsequent searching in the remaining two days brought to light twenty-seven more dead tortoises in holes and fissures, and there must have been very many more that were not found. These fissures, which are numerous, are sometimes quite narrow, and must often be concealed in the wet season when the grass is thick. From his examination of the terrain and the 
present state of the vegetation, Sr. Castro formed the opinion that through shortage of food in the lower areas the tortoises had been forced to move up into the more humid zone, thus crossing areas where fissures are numerous, and that these forced movements resulted in such heavy mortality that the population was finally unable to replace its losses and extinction followed.

When Bowman and Eibl-Eibesfeldt visited Abingdon in 1957, there were no goats, but some time between then and 1963 they were most unfortunately introduced, presumably by fishermen who wished to provide meat for their future fishing expeditions. By March, 1963, they were already quite numerous locally, but clearly still in the early stages of expansion. By May, 1964, the vegetation of the lower areas had already been badly affected on the south side of the island, where tortoises used to live and probably had their nesting places. However, it is uncertain to what extent the goats can have been responsible for the disaster which has befallen the Abingdon tortoises. As mentioned above, they were already rare in 1906. Although it is not known how quickly a dead tortoise in a fissure will decay, most of those found seemed to be more than five years old. It may be that increasing aridity was the main cause of the forced movement to the higher levels, while the introduction of goats may have administered the coup de grâce. At all events, it must now be considered as probable that the Abingdon tortoise no longer exists in the wild state.

Hood.-The Academy Expedition spent nine days searching for tortoises on Hood in 1906 and found only three. Hood was one of the islands from which huge numbers were taken by the whalers and Van Denburgh justly concluded : "Evidently they have been well cleaned out." Some however still survived. In 1930 Townsend reported that "two specimens of the Hood Island tortoise (Testudo hoodensis) until recently believed to be extinct, were obtained by the Pinchot Expedition of 1929 ..." After that, nothing was known of the fate of the Hood tortoise, except for rumours that they were still very occasionally taken by fishermen from Chatham (San Cristobal) up to fifteen or twenty years ago. For over sixty years Hood has been overrun by goats and its vegetation has been greatly impoverished.

Personnel of the Research Station made three expeditions to Hood in 1963, of which one of the main objectives was to find out if any tortoises still survived. On July 25 th a day was spent searching a likely area inland from the middle of the north coast, where the early tortoise hunters used to land, but without success. On August 30th and 31st a party of four searched extensive areas in the centre and west of the island, leading to the discovery by $M$. Castro, on the 31st, of a single tortoise on the northern side of the highest hill, in the west-central part of the island. It was apparently a male, measuring $56 \mathrm{~cm}$. along the curve of the carapace. To illustrate the desperate state to which both the tortoises and the goats of Hood have been reduced, it need only be said that when found, this tortoise was chewing the pieces of a fallen Opuntia in company with fifteen goats. The pads had already been finished and they were starting on the trunk. 
On November 23rd and 24th the writer and $M$. Castro, with two others, again searched extensively, this time in the central and east-central parts of the island, and on the 24th Sr. Castro again found a single tortoise, resting in the shade of an Opuntia, in the east-centre of the island and about $2 \mathrm{~km}$. from where the first was found. This one, of undetermined sex, measured $59 \mathrm{~cm}$. along the curve of the carapace. Finally, from July 21 st to 23rd, 1964, Sr. Castro again searched likely areas on Hood and found only the tortoise which had been marked on August 31st, 1963.

From the considerable area of Hood that has now been fairly thoroughly searched, it may be guessed that the total population cannot be much above twenty individuals. The devastation of the perennial vegetation by the goats and the extreme dryness of recent years, resulting in a poor growth of grasses and other annuals, makes their continued survival very doubtful, unless the goat population can be exterminated or at least substantially reduced. In view of the seriousness of the situation, the Research Station plans to begin an intensive campaign against the goats in the near future.

Chatham and Charles (Floreana).-These two islands have been inhabited much longer than any others. The Charles Island tortoise became extinct long ago, and it has been generally assumed that the Chatham tortoise, which seemed to be almost extinct at the time of the Academy Expedition, has now disappeared. Nothing in fact was definitely known until Sr. Jacob Lundh, a keen naturalist and resident of Chatham, heard rumours of the continued existence of tortoises in a little visited part of the island away from the main settled area, and decided to investigate. In May and June, 1964, he spent six days in some of the most likely country, and though he did not see any tortoises in the wild he secured positive evidence that the Chatham tortoise survives and, at least up to about five years ago, was still breeding successfully, as he found that a family cultivating a remote small holding had two young tortoises which they had found in the neighbourhood and which Sr. Lundh judged to be not more than five years old. He also heard of a few others being kept as pets, but was unable to see them in the time available to him.

\section{The Future of the Tortoises}

Before discussing the future chances of survival of the Galapagos tortoises, it is worth while taking stock briefly of the present position as revealed by the admittedly very incomplete investigations that have been described above. Omitting Jervis, where it is very doubtful that there ever was a native tortoise, ten islands originally had tortoises (Abingdon, Albemarle, Barrington, Charles, Chatham, Duncan, Hood, Indefatigable, James and Narborough), Albemarle having five distinct races. Thus there were altogether fourteen distinct races. Although the fear has often been expressed in the last thirty years, with much to justify it, that they were all doomed in the wild state, and it has been stated by one author or another that they are already extinct on all but two or three islands, in fact our investigations have shown that only Barrington and Charles have definitely lost their native tortoises, while Abingdon may have done so ; and the extinction of the Barrington and Charles tortoises took place long 
ago. Thus of the fourteen distinct races, only two or three are extinct in the wild state. The results of this initial survey are more gratifying than might have been expected, but give no cause for complacency, since the position of several of the surviving populations is extremely precarious.

What are the main dangers threatening the surviving tortoises, and what measures must be taken for their protection? The direct threat from man as predator, while not by any means past, is now of secondary importance. On Indefatigable, where man's colonisation might otherwise quite easily have led to the disappearance of the tortoises, the creation of a special reserve, the enforcement of the very adequate laws and decrees, and the gradual spread of a more educated public opinion should soon combine to reduce human depredation to an unimportant level. On Albemarle, the only other island where considerable human and tortoise populations both exist, the long distances and difficult terrain effectively protect three of the tortoise populations (those of Volcan Darwin, Volcan Alcedo, and Cerro Azul). The tortoises of Sierra Negra, however, are probably still subject to human predation, and the population of Volcan Wolf, in the extreme north, are rather easily accessible from the sea and need special protection, at least in the nesting season. On the other islands where tortoises still survive, the direct threat from man now seems to be negligible, except perhaps on Chatham where the situation needs further study. Probably few fishermen now bother to climb the extremely unpleasant slopes of Duncan to reach the upper zone where the tortoises live, and certainly none now think it worth while to hunt for the few tortoises that remain on James and Hood.

\section{A Persistent and Increasing Threat}

By contrast, introduced animals constitute a persistent and on some islands an increasing threat. On Hood, where goats have been established for a long time, the situation is so serious for the tortoises, as well as for the native vegetation, that prompt measures are necessary if there is to be any hope of survival. On Indefatigable, a sustained campaign against pigs, and secondarily goats, is desirable in order to ensure the survival of the comparatively flourishing population. On Duncan, effective control of the rats is urgent. On Albemarle, the tortoises of the two southern volcanoes are probably in much the same position with respect to introduced animals as are those of Indefatigable, with dogs as additional predators. The spread of introduced animals on the middle volcano, Volcan Alcedo, needs to be investigated. It can be hoped that the barren lava fields will continue to protect the two northern volcanoes. On James, the remnants of the tortoise population must certainly be competing for food with the abundant goats, and perhaps are preyed upon by pigs ; but the situation is little known. Only on Narborough is the influence of man, direct or indirect, still unfelt. It is all the more ironical that on this island alone volcanic activity may have effectively destroyed the tortoise population and so have accomplished what man was unable to do.

Finally, it must be recognised that the remnants of populations which were thoroughly exploited by tortoise hunters may no longer be viable, even if all the adverse factors are controlled, since they may consist only 
of old animals, and especially old males. This may be the state of the James and Hood tortoise populations. However, Galapagos tortoises have a surprising ability to survive, and to turn up again after being thought to be extinct ; so that it would be wrong not to take all possible measures for their protection, even in islands where the situation may appear hopeless.

Acknowledgments. - Most of the field work on which this account is based was carried out by personnel of the Charles Darwin Research Station, chief among whom must be mentioned Sr. Miguel Castro, a tireless field worker, who took part in nearly all the expeditions and was responsible for many of the more notable discoveries, including both the tortoises found on Hood and most of those found on Duncan. I am also indebted to Mr. David Cavagnaro, Dr. E. Curio, Dr. J. Hendrickson, and Mr. Jacob Lundh for unpublished information; and to Gusch, Carl and Fritz Angermeyer of Academy Bay for showing me the population of saddle-backed tortoises in the north-west of Indefatigable.

\section{REFERENCES}

BoWman, R. I., 1960. Report on a biological reconnaissance of the Galapagos Islands. UNESCO Report, Paris.

Dowling, H. G., 1962. World's end revisited. Animal Kingdom, 65 : $130-142$.

EIBL-EIBESFELDT, I., 1959. Survey on the Galapagos Islands. UNESCO Mission Reports, No. 8.

LÉvÊQUe, R., 1963. La statut actuel des vertébrés rares et menacés de l'archipel des Galapagos. La Terre et la Vie, no. 4-1963: 397-430.

Townsend, C. H., 1925. The Galapagos tortoises in their relation to the whaling industry : a study of old logbooks. Zoologica, 4 : 55-135.

TownsEND, C. H., 1930. The Astor Expedition to the Galapagos Islands. Bull. New York Zool. Soc., 33 : 135-155.

VAN Denburgh, J., 1914. The gigantic land tortoises of the Galapagos Archipelago. Proc. Calif. Acad, Sci., 2: 203-374.

\section{Rules for Pesticides in the U.S.A.}

STRINGENT rules regarding the use of pesticides on the 500 million acres

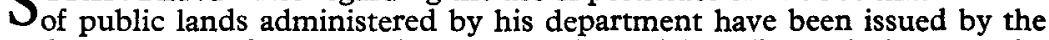
U.S. Secretary of the Interior, Stewart L. Udall. First priority must be given to non-chemical methods of pest control, and safety is to be the first consideration when chemicals are considered essential. Only chemicals required for use on a particular pest may be used, and instructions for use must be carefully followed. State and local authorities are to be informed when chemicals are to be used. The most selective chemicals must be used, with minimum dosages and under conditions that minimise harmful effects, and compounds known to concentrate in living organisms, such as DDT, chlordane, dieldrin and endrin are to be avoided.

Two states, Illinois and Indiana, are conducting experiments with tiphia wasps from Japan for controlling a destructive "fellow-countryman ", the Japanese beetle. The wasp females sting the beetle grubs in the soil and deposit eggs in their paralysed bodies. On hatching the wasp grub eats the beetle grub. Hitherto the beetles have been controlled by pesticides. 